\title{
The Practice of the Project Teaching Method in the Course of Engine Mechanical System Maintenance
}

\author{
Leiming $\mathrm{Shi}^{1}$; Yajie $\mathrm{Li}^{2}$ \\ 1.Motor College 2.Communication College \\ Henan Communication Vocational Technology College \\ Zhengzhou, China \\ Shileiming2006@163.com
}

\author{
Di Zhang \\ Department of Social Sports \\ Physical Education College of Zhengzhou University \\ 1 Zhengzhou, China \\ Zhangdi1971@163.com
}

\begin{abstract}
In this paper, according to the characteristics of the project teaching method, by the account of the teaching process and teaching effect of the application of project teaching method in the practice teaching of the Engine Mechanical System Maintenance(EMSM), combining the practice and experience, the several problems needing to pay attention to was put forward during the project teaching. And the corresponding solutions was also put forward. It has certain directive significance to set up a new teaching model for improving EMSM course teaching effect.
\end{abstract}

Key words-Project teaching method; Engine; Mechanical system; Maintenance.

\section{INTRODUCTION}

The fundamental task of higher vocational education is cultivating the highly skilled professionals to adapt to the modernization and high-quality workers, training the practical talents of the first line for production and social practice. So as for undergraduates, It is very important for mastering learning methods and improving social adaptation ability [1].

But the traditional teaching mode is "cramming" teaching. On the one hand, the teaching content is completely organized by the teacher according to the teaching material. Student's learning needs are seldom considered. The students are often passive learning. The content is only confined to the classroom theory infusion. On the other hand, the students' classroom learning is consolidated. It is mainly through the consolidation of copying and understanding and memory finish. The students are easy to develop the study habits of test evaluation with "recite" to solve. It is the purpose for the "Written Examination" for students' classroom assessment method. For part of the active students, it greatly hurt their learning initiative[2]. The practice course is only arranged in the stage of graduation. The school training room utilization rate is very low. Theory is considered to be important. The ability to do is ignored. The theory and the practice phase is separate. These factors seriously hindered the improvement

This is the research planning project of humanities and social science of Henan Province Office of Education (Marx's theory of subject) (Grant No 2012-MGH-018).And also research key project of Humanities and social science of Henan Province Office of Education (Grant No 2012$\mathrm{GH}-329$ ) of students' comprehensive ability and the professional environmental adaptation capability[3]. In recent years, it is project teaching for the teaching mode of a aims to cultivate college students' analysis ability to solve practical problems. It has been the attention of education field at home and abroad. And also become the ideal choice for higher vocational teaching reform

\section{THE BASIC PRINCIPLE OF PROJECT TEACHING METHOD}

The project teaching method is also known as "research learning based on project activities". It has been widely promoted in the current educational circles. Especially for the effects of occupation education, it is more obvious. The project teaching method is facing to "project" in the form of teaching. Teaching is driven through(by) the project[4]. Students complete the whole process of a project under the guidance of teachers. They learn and master the teaching content covered by teaching plan in the process. In the project teaching method, the students should be all or part of the organization, do learning activities, complete processing of the project details and overcome difficulties encountered. The famous Swiss psychologist Jean Piaget proposed constructivism learning theory. He thought that knowledge acquired is not taught by teachers to get[5]. But the students with the help of others in certain circumstances, using the necessary learning materials, get through the meaning construction way.

The ideas and characteristics of the three kinds of teaching methods(Inquiry teaching method, task-based teaching method and case-based teaching) is referenced by the project teaching method. The learning situation is created by the selection program. The way of learning is carried out by cooperative learning. The achieve meaning construction is done by the completing the project. There are three prominent changes by comparing this kind of teaching mode with the traditional teaching mode. The first is with the teacher as the center into student-centered. The second is in teaching material as the center to turn into the project as the center. The third is in the classroom teaching as the center to change in practice as the center. The teaching is carried on with the completion of the project. The environment of appropriate students' creativity development and the performance can fully be reflected and built in the teaching. 
The teacher should encourage the students to fully show their ideas. The student's innovative potential is fully developed. The central concepts and principles of a subject is focused on by the project teaching method. Its aim is to bring students into meaningful task completion process, let the students learn actively and get independent on the construction of knowledge.

The implementation of the project teaching method step was shown in figure 1 shows.

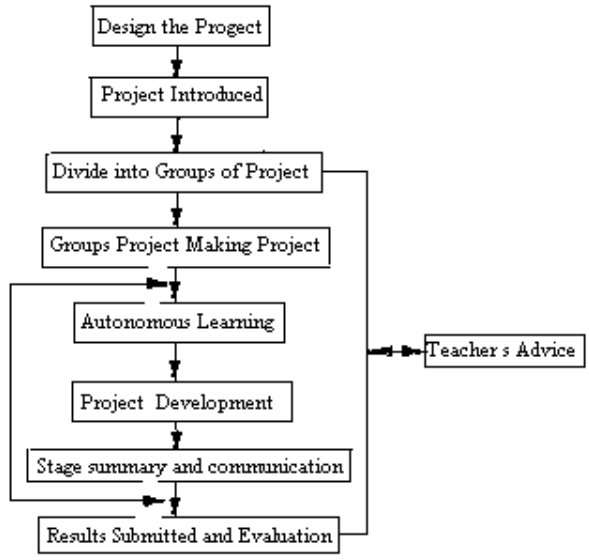

Figure 1 The project teaching method step

\section{III.TEACHING EXAMPLE}

When students studied the part of study content of connecting rod inspection and correction of Engine Mechanical System Maintenance. As the engine working conditions was complex and its load changed frequently in the actual work process. The connecting rod is the important middle connecting body to realize the reciprocating motion of the piston to the crankshaft rotation transformation. Therefore, it is in complex stress. The students were not easy to master theory of bending and twisting. So I used the project teaching method to teach them. At first, I taught them from the simple structure and function and so on in the multimedia classroom. Secondly, With the help of the video published openly and the video made by ourselves, let the student learn in the form of project tasks. The learning focus is on the connecting rod bending and twisting. And actual objects were used to explain to students. Then, removing to training classroom nearby, it was the next step in learning project. In the test bench, the teacher and the experimentalist personally gave test demonstration of the steps of the connecting rod bending and twisting. Students were guided to think independently. After that, the students began to detect connecting rod with instrument. And the bending and distortion connecting rods were corrected. The project report with work sheet was completed by mutual cooperation. In enterprise, The work sheet is needed table when enterprise boss arrange work for technical workers. There is work steps on it. This imitated the enterprise to do. Through the practice and thinking repeatedly, students' innovative thinking ability and practice ability were trained well. The
Connecting rod assembly and Connecting rod and connectivity were referred as figure 2 and $3[6]$.

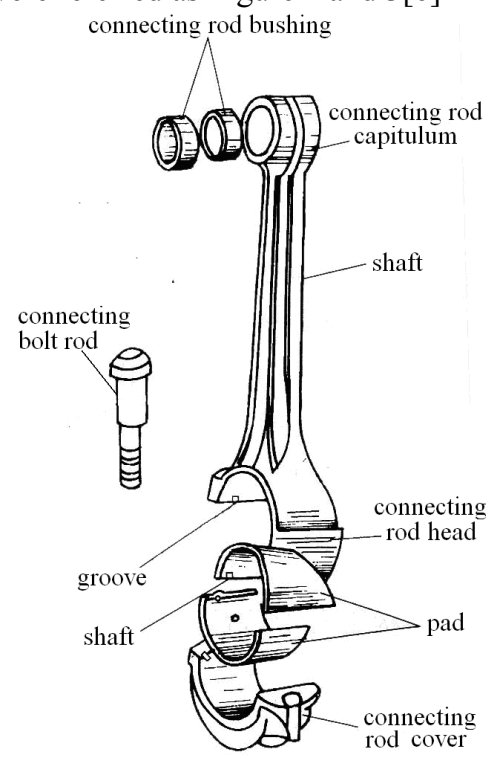

Figure 2 Connecting rod assembly

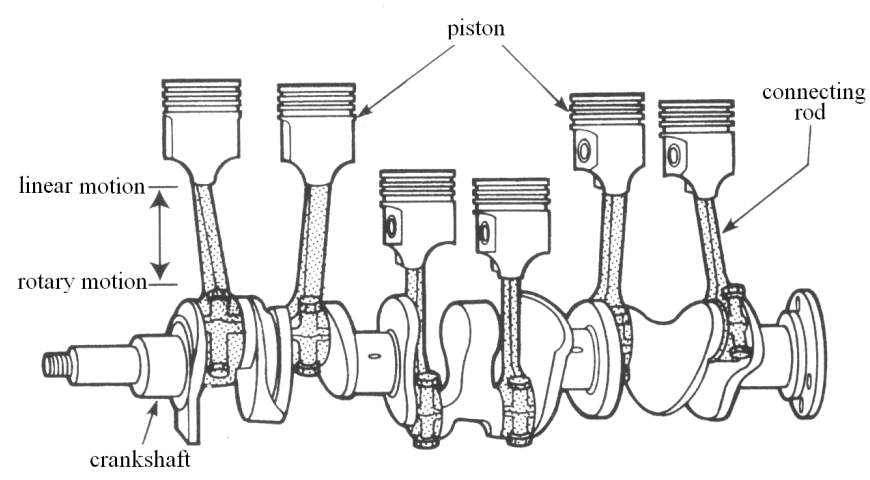

Figure3 Connecting rod and connectivity

Teaching examples: The project teaching method of Engine Mechanical System Maintenance

Field of study: The connecting rod of piston and connecting rod assembly

Unit of learning: The inspection and correction of connecting rod

Target group: The Class 11305 of vehicle maintenance and repair

Teaching point: Engine multimedia classrooms and training rooms on the same floor

Teaching aims: 1.Knowledge goals: The students watched the structure schematic diagram and the video link production. They needed understand name of each component. They could describe their work principle and structure. 2.Ability goals: Students could measure rod bending and twisting by test instrument. They could also correct rod bending and twisting by calibrating instrument. 
Team spirit of students is cultivated through mutual discussion.

Teaching aids: Cylinder local section of the cutting engine with motor driving; Connecting rod material; The connecting rod force diagram.

Teaching materials: Each a project task list containing a table of contents.

Safety: Abiding by the safety operation specification of repair workshop; Gently, didn't damage the components and instruments; Avoiding to injure himself and the same group of people; Didn't fall to the ground in the use of instruments.

Teaching process:

(1)Design project: The students understood the linkage structure diagram. Knew each component part name. Understood their work principle. Were skilled in the use of instruments for detecting and correcting rod bending and twisting

Project introduction: According to the dynamic engine, could tell the effect of the connecting rod. Analysis of causes of deformation. After the connecting rod bent and twisted, test methods, steps and correction methods. To complete the inspection and correction operation, Complete work order (by himself) content required and learning summary fill (one for each team)

(3)The groups of students : A group of every 5 people; A total of 8 groups .

(4)Group project making project: Group and its members work item; Cleared learning objective; Completed the project work steps.

(5)Autonomous learning, Project development

a. The Connecting rods assembly were recognized from the outside. The students observed their external structure all what the characteristics are. A representative of each group answered what he saw, which was recorded down.

b. Dynamic engine working process was observed carefully by the students that knew the piston connecting rod set and related connection.

c. On the basis of the knowledge learned, the students looked for the cause of the deformation of bearing connecting rod by contrast with element.

d. By watching the video and observing teacher demonstrates, the students used connecting rod bending and twisting tester to test rods. The connecting rod bending and twisting was referred as figure 4[6].

e. By watching the video and observing teacher demonstrates, bending and twisting connecting rods were corrected by the students to use of connecting rod bending and twisting correction instrument. The connecting rod distortion correction was referred as figure 5 . The connecting rod bending calibration was referred as figure 5 [6].

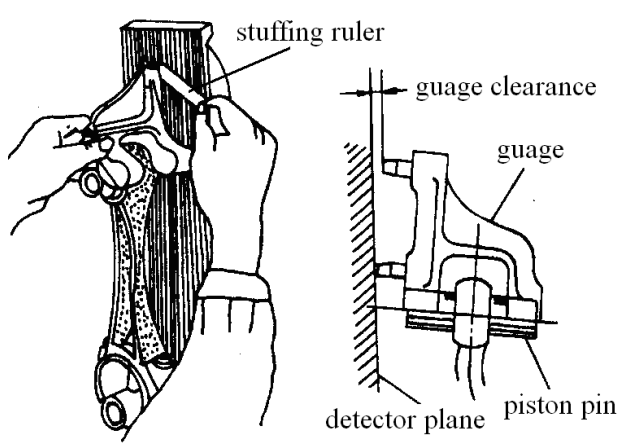

Figure 4 Connecting rod bending and distortion tes

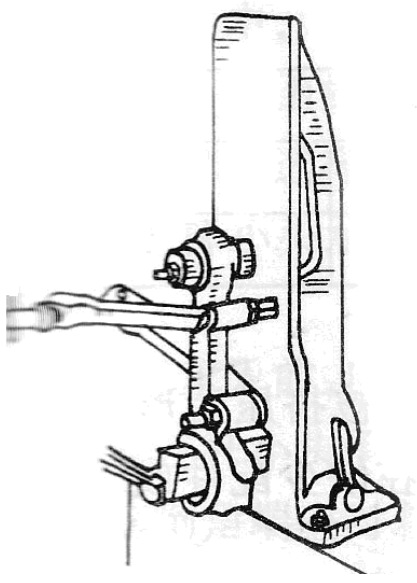

Figure 5 Connecting rod twisting calibration

f. Assessment: Each group randomly took two students for assessment randomly. A student is for simple theoretical examination. The other student is for real operation evaluation. The two results accounted for $30 \%$ and $70 \%$ respectively. They were added up as the result of the group. The focus of the assessment is to emphasize ability.

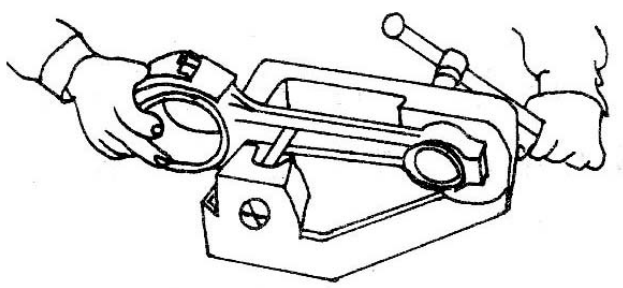

Figure 6 Connecting rod bending calibration

(6) Stage summary and communication

a. Group summary and evaluation: Discussing by this project process, what understanding did the students have for connecting rod inspection and correction? What difficulties did they meet in practice project? How were problems solved? What content they still wanted to know? Whether did each member of the group understand the project 
implementation plan? Was each member actively involved in the team for the project?

b. Teachers' own summary and reflection: What problems and difficulties did it exist for each teaching link in the process of implementation. How were these problems and difficulties solved? The improvement opinions of the next activity were put forward.

c. The teacher's summary and evaluation facing to student: The teacher recorded the key points to every group's speaking and had summarizes. Finally, it was completed for the knowledge points and real operating essentials of whole class.

(7) Results submitted and evaluation:

a. Each project table including work sheet must be completed by the students.

b. The teacher pointed out the students' positive performance and the common problems of the knowledge and skills in the process of the project. According to the problems in activity, the teacher stressed or put forward corresponding discipline requirements. It was ensured that the next activity can be done successfully

It could not be controlled very well by this method in time. This depends on the students' quality and the teachers' inspiration level. The teachers need a lot of preparation and teaching organization work. The practice has proved that project teaching method is a good teaching effect.

\section{NEEDING TO PAY ATTENTION TO THE PROBLEM OF THE IMPLEMENTATION OF THE PROJECT TEACHING METHOD}

\section{A. Pay attention to the choice and design of project}

Good project selection and design scheme is the premise condition and the important guarantee to realize the teaching goal effectively. In the choice and design project, the following principles should be grasped: The project should reflect the combination of the theoretical knowledge course and practical skill. The project should also have a direct relationship with the actual production process or practical activities. Each project takes different difficulty level and different size. They must form a certain independence. During the designing project, their connected relationship should be considered in the course systematic and the characteristics of the ability training. And should have clear and specific results show in each project; The project products make a certain expression force as far as possible. Intuitive impression is easy to make students have a sense of accomplishment. It is good to cultivate the students' interest in learning and to improve the efficiency and effect of project teaching.

\section{B. High quality requirements to the teachers and the} students

The teachers must have the solid fundamental knowledge of the subject to implement project teaching well. And they should also have the knowledge and ability about the project planning, project management and project evaluation. It must be considered about the match of the members, division of work and the number of people in the course of the project implementing for the students. It is gradually cultivated for the students' self-management and self-learning ability.

\section{The use of teaching materials}

The current teaching materials are mostly according to this discipline knowledge system to write. They can not meet the needs of the project teaching method. Teachers must not teach the students according to the order of the teaching material in the implementation of project teaching. But they should select and design some teaching project to teach according to the teaching material content. They also combine the reality of the college to compile internal materials of the project type to cooperate with the implementation of the project teaching. For example, In our school, the teachers have prepared a set of project type teaching according to the school physical truth of software and hardware. And the set of project type teaching have published by Harbin Engineering University Press. The project work sheets will be published by Henan Science Press. It can make project teaching materials more enrich and to make up for the lack of teaching materials of the higher vocational colleges in the project type

\section{Project evaluation to have timeliness}

The design of scheme evaluation should be reasonable and fair. The teachers should pay attention to students' skills process and effect to the students' evaluation. So we cultivate students' interest of study and correct learning attitude. This is the goal of teaching. The thought of "ability as the standard" must be carried out in teaching practice. The project task will be used as a unit in the project teaching method. It will throughout the whole teaching by the teachers' demonstration and the students' practice and training. The teaching is implemented by the reasonable teaching steps, teaching plan and evaluation scheme, which is very effective to improve the teaching quality of the course and cultivate students' innovative thinking and ability.

\section{REFERENCES}

[1] Chen Li, "Study on moderate scale of occupation education,"D. Southwestern University of Finance and Economics, 2009. 11, pp105-114.

[2] Song Fang, "Economic and social Indispensable skills,"J. Contemporary Economy, 2008.2, pp74-77.

[3] .He Kehang, "The theoretical foundation of constructivism -- to Reform the Traditional Teaching,"J. Audio-visual education research,1997.3, pp89-92.

[4] Wu Yan, "The project teaching method,"J.occupation technology Education,2003.03, pp50-53.

[5] Luo Yunhui, "The project teaching method in the implementation and effect of the automobile profession,"J.Chinese occupation technology education,2006.6. pp123-126.

[6] Shileiming, "Engine mechanical system maintenance,"M. Harbin Engineering University Press, 2008.2, pp2. 